\title{
Thyroid Hormone Controls Cone 0psin Expression in the Retina of Adult Rodents
}

\author{
Anika Glaschke, ${ }^{1}$ Jessica Weiland, ${ }^{2}$ Domenico Del Turco, ${ }^{2}$ Marianne Steiner, ${ }^{3}$ Leo Peichl, ${ }^{1}$ and Martin Glösmann ${ }^{1,4}$ \\ ${ }^{1}$ Max Planck Institute for Brain Research and ${ }^{2}$ Institut für Klinische Neuroanatomie, Neuroscience Center, Goethe-Universität, 60528 Frankfurt/Main, \\ Germany, ${ }^{3}$ Center for Anatomy and Cell Biology, Medical University of Vienna, 1080 Vienna, Austria, and ${ }^{4}$ VetCore-Core Facility for Research, \\ VetImaging Unit, University of Veterinary Medicine, 1210 Vienna, Austria
}

\begin{abstract}
Mammalian retinas display an astonishing diversity in the spatial arrangement of their spectral cone photoreceptors, probably in adaptation to different visual environments. Opsin expression patterns like the dorsoventral gradients of short-wave-sensitive (S) and middle- to long-wave-sensitive (M) cone opsin found in many species are established early in development and thought to be stable thereafter throughout life. In mouse early development, thyroid hormone (TH), through its receptor TR $\beta 2$, is an important regulator of cone spectral identity. However, the role of TH in the maintenance of the mature cone photoreceptor pattern is unclear. We here show that TH also controls adult cone opsin expression. Methimazole-induced suppression of serum TH in adult mice and rats yielded no changes in cone numbers but reversibly altered cone patterns by activating the expression of S-cone opsin and repressing the expression of M-cone opsin. Furthermore, treatment of athyroid Pax $8^{-1-}$ mice with TH restored a wild-type pattern of cone opsin expression that reverted back to the mutant S-opsin-dominated pattern after termination of treatment. No evidence for cone death or the generation of new cones from retinal progenitors was found in retinas that shifted opsin expression patterns. Together, this suggests that opsin expression in terminally differentiated mammalian cones remains subject to control by $\mathrm{TH}$, a finding that is in contradiction to previous work and challenges the current view that opsin identity in mature mammalian cones is fixed by permanent gene silencing.
\end{abstract}

\section{Introduction}

Most mammals have two types of cone photoreceptors (reviews: Ahnelt and Kolb, 2000; Peichl, 2005). Their spectral identity is specified by the opsin they express, short-wave (S) or middle- to long-wave sensitive (M). S- and M-cones develop from cone precursors that have the potential to express either opsin; a choice is made by differential regulation (Szél et al., 1994; Applebury et al., 2000; Cornish et al., 2004). The spectral identity and the retinal distribution of S- and M-cones, once specified, are thought to be rigidly preserved to support visual functions such as contrast and color vision. In mouse early postnatal development, thyroid hormone $(\mathrm{TH})$, through its receptor $\mathrm{TR} \beta 2$, is an important regulator of cone spectral identity by repressing S-opsin and activating M-opsin (Ng et al., 2001; Roberts et al., 2006; Applebury et al., 2007; Pessôa et al., 2008; Lu et al., 2009, Glaschke et al., 2010). In the adult retina, however, the role of TH signaling in opsin regulation is unclear, despite an abundance of hormone (Ientile et al., 1984; Roberts et al., 2006) and the persistent, albeit low expres-

Received Nov. 26, 2010; revised Jan. 26, 2011; accepted Jan. 29, 2011.

This work was supported by Deutsche Forschungsgemeinschaft Grant PE 38/16. We thank K. Bauer and H. Heuer (Leibniz Institute for Age Research, Jena, Germany) for providing Pax ${ }^{+/-}$founder mice and S. Heynck and H. Korff for technical assistance. D. I. Vaney (Queensland Brain Institute, Brisbane, Queensland, Australia) and C. L. Makino (Harvard Medical School, Boston, MA) provided comments on this manuscript. J. Nathans (Johns Hopkins University School of Medicine, Baltimore, MD) donated the JH492 antiserum.

Correspondence should be addressed to Dr. Martin Glösmann, VetCore — Core Facility for Research, Vetlmaging Unit, University of Veterinary Medicine, Veterinärplatz 1, 1210 Vienna, Austria. E-mail: martin.gloesmann@ vetmeduni.ac.at.

DOI:10.1523/JNEUROSCI.6181-10.2011

Copyright $\odot 2011$ the authors $\quad 0270-6474 / 11 / 314844-08 \$ 15.00 / 0$ sion of TR $\beta 2$ in cones (Applebury et al., 2007; Fujieda et al., 2009; $\mathrm{Ng}$ et al., 2009).

The present study aimed at elucidating whether TH continues to control opsin expression in mature cones. To address this issue, we used two rodent models that strongly differ in their adult cone opsin expression patterns and used two paradigms of adult-onset hypothyroidism, followed by an analysis of gene expression using quantitative PCR (qPCR) and immunohistochemistry. Pharmacological suppression of serum TH in adult mice and rats reversibly altered cone patterns by activating the expression of S-opsin and repressing the expression of $\mathrm{M}$-opsin in cones. Furthermore, treatment of athyroid Pax $8^{-1-}$ mice with $\mathrm{TH}$ restored a wild-type pattern of cone opsin expression that reverted back to the mutant $\mathrm{S}$-opsin-dominated pattern after termination of treatment. The findings, which contradict previous work, suggest that cone opsin expression remains subject to control by $\mathrm{TH}$ throughout life and challenge the current view that opsin identity in mature mammalian cones is fixed.

\section{Materials and Methods}

Experimental animals and chemical treatment. All procedures strictly complied with the National Institutes of Health Principles of Laboratory Animal Care and the corresponding German laws, and were performed as approved by the local committee on animal experimentation.

Adult male mice (C57BL/6J; Charles River) and rats (Brown Norway; Elevage Janvier) were purchased at 10 weeks of age and allowed 2 weeks to acclimate. Animals were maintained on a $12 \mathrm{~h}$ light/dark cycle and provided with standard laboratory feed and water ad libitum, except where indicated otherwise. At 12 weeks of age, experimental animals were rendered hypothyroid (hypothyroid group, $n=20$ ) using $0.074 \%$ 
Table 1. TaqMan gene expression assays used for quantitative real-time RT-PCR

\begin{tabular}{llll}
\hline Gene symbol & Assay ID $^{a}$ & Amplicon size (bp) & GenBank \\
\hline Hprt & Mm01318743_m1 & 125 & NM_013556 \\
Rho & Mm00520345_m1 & 86 & NM_145383.1 \\
Opn1sw & Mm00432058_m1 & 64 & NM_007538.2 \\
Opn1mw & Mm0043560_m1 & 87 & NM_008106.2 \\
Dio2 & Mm00515664_m1 & 77 & NM_010050.2 \\
Dio3 & Mm00548953_s1 & 120 & NM_172119.2 \\
Thrb2 & Mm00437042_m1 & 70 & NM_009380.3 \\
Nrl & Mm01321143_m1 & 88 & NM_008736.2 \\
Nr2e3 & Mm00443299_m1 & 90 & NM_013708.4 \\
\hline
\end{tabular}

apart number (Applied Biosystems).

\section{Methimazole model of adult hypothyroidism}

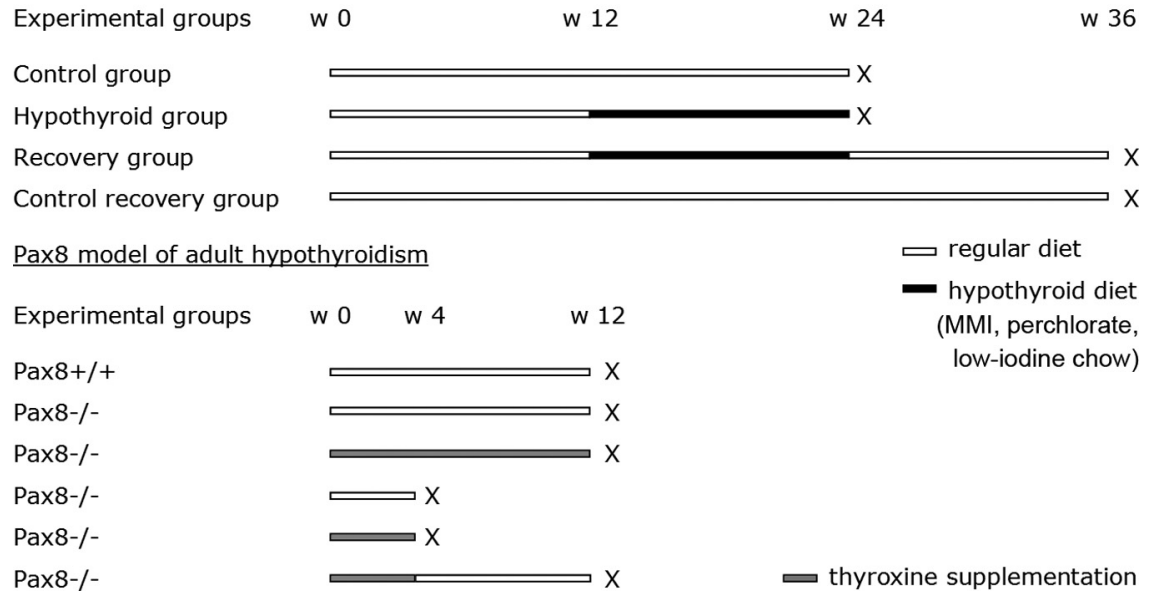

Figure 1. Experimental models of adult-onset hypothyroidism. w, Postnatal week.
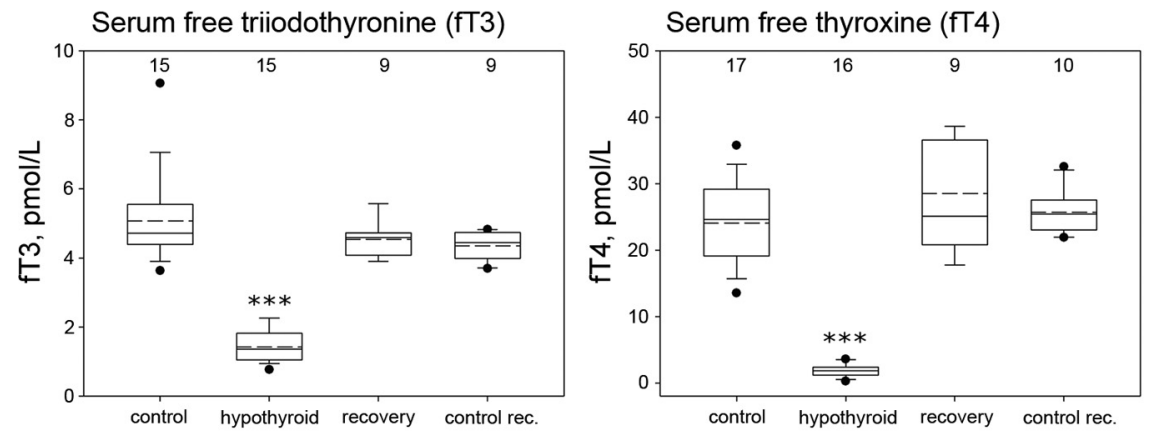

Serum total triiodothyronine (tT3)
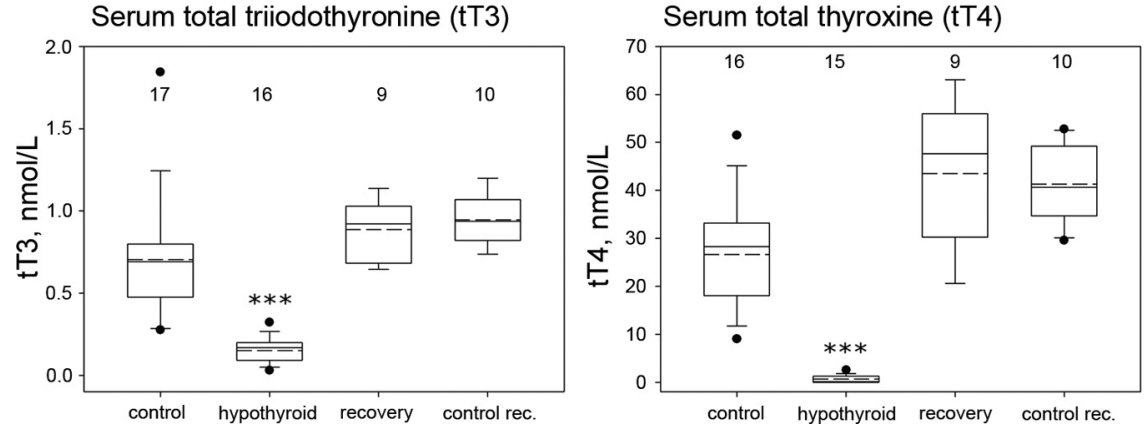

Figure 2. Serum iodothyronine levels of $\mathrm{C} 57 \mathrm{BL} / 6 \mathrm{~J}$ mice used for cone opsin immunostaining. For description of the groups, see Figure 1. The top and bottom lines of the boxes correspond to the 75th percentile and 25th percentile, respectively. The solid lines represent median hormone levels. The dashed lines indicate the arithmetic mean. Minimum and maximum observations are indicated as filled circles. Numbers of samples are indicated above each whisker box. Data were compared using Kruskal-Wallis one-way ANOVA on ranks and Bonferroni's $t$ test for post hoc pairwise multiple comparison. ${ }^{* * *}$ Significantly different from control, recovery, and control recovery groups with values of $p<0.001$ at $\alpha=0.05$. methimazole (MMI), $0.74 \%$ sodium perchlorate, $26 \%$ raspberry syrup diluted in drinking water together with low-iodine diet (Ssniff). Control animals (control group, $n=20$ ) received water without MMI/perchlor12 weeks, 10 animals of each group were killed by decapitation and their eyes were prepared for immunohistochemistry. The remaining animals (recovery group, control recovery group) (see Fig. 1) were reopsins. Animals used for reverse transcription-quantitative real-time using $0.03 \% \mathrm{MMI}$ and $1 \%$ sodium perchlorate in drinking water together with low-iodine diet. Control animals $(n=6)$ received water without $\mathrm{MMI} /$ perchlorate. After 8 weeks, animals were killed, and their retinas were prepared for mRNA extraction.

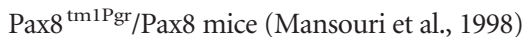
were provided by Karl Bauer and Heike Heuer (Leibniz Institute for Age Research, Jena, Germany) and bred at our institute. Genotypes of pups were determined by PCR analysis of genomic DNA isolated from tail samples. Experiments were performed on young Pax $8^{-1-}$ mice kept with their mother or on older animals kept with their littermates. Pax $8^{-1-}$ mutants received daily subcutaneous injections of $18 \mathrm{ng}$ of thyroxine (T4)/g body weight from postnatal weeks 0 to 4 , or from postnatal weeks 0 to 12 (see Figs. 1, 5). Control, $\mathrm{Pax} 8^{+/+}$mice were injected with saline lacking T4. At postnatal week 12, animals were killed by decapitation and subject to cone opsin double immunofluorescence.

Serum iodothyronine analysis. To confirm hypothyroidism, trunk blood was collected from all animals and serum iodothyronine levels were determined by competitive immunoassay (ACS:180; Bayer Health Care) with detection limits of $0.3 \mathrm{pmol} / \mathrm{L}$ for free triiodothyronine (fT3), $1.3 \mathrm{pmol} / \mathrm{L}$ for free thyroxine (fT4), $0.3 \mathrm{nmol} / \mathrm{L}$ for total T3 (tT3), and 6.4 $\mathrm{nmol} / \mathrm{L}$ for total T4 (tT4).

Immunohistochemistry. Eyes were fixed in $4 \%$ paraformaldehyde/ $0.1 \mathrm{~m}$ phosphate buffer. Retinas were dissected and blocked, and cone opsins were detected using polyclonal rabbit anti-M-opsin (JH492) (Wang et al., 1992) and polyclonal goat anti-S-opsin (sc-14363; Santa Cruz Biotechnology) as described previously (Glösmann et al., 2008; Glaschke et al., 2010). Sampling of retinal regions for comparison of cone opsin patterns between experimental and control animals followed that of Glaschke et al. (2010). Polyclonal rabbit anti-mouse active caspase 3 (AF835; R\&D Systems) and monoclonal rabbit anti-Ki67 (clone SP6; RM-9106; Thermo Fisher Scientific) were used to identify apoptotic and proliferating cells, respectively, in frozen sections of adult retina. Programmed cell death was also detected using the In Situ Cell Death Detection Kit, Fluorescein (11684795910; Roche Applied Science), according to the manufacturer's protocol. Retinas from newborn mice that exhibit apoptosis and cell proliferation served as positive controls. Retinas were coverslipped and viewed on a Zeiss Axio Imager.Z1 (Zeiss).

RNA extraction and reverse transcriptionquantitative real-time PCR. Total RNA was extracted from MMI-treated $(n=6)$ and control mouse retinas $(n=6)$ using the RNeasy Plus Mini Kit (QIAGEN) according to the manufacturer's protocol. RNA quality was assessed us- 
ing an Agilent 2100 bioanalyzer and the RNA 6000 Nano LabChip Kit (Agilent Technologies). Only RNA with RNA integrity number $(\mathrm{RIN}) \geq 8.50$ was used for additional analysis (MMI, $n=4$; control, $n=6$ ). Single-stranded cDNA was synthesized using the High Capacity cDNA Reverse Transcription Kit (Applied Biosystems) following manufacturer's recommendations. cDNA samples were used as templates for TaqMan-based quantitative PCR in $15 \mu \mathrm{l}$ volumes on a StepOnePlus Real-Time PCR System with the TaqMan Gene Expression Master Mix (Applied Biosystems) and the TaqMan Gene Expression Assays listed in Table 1. Cycling parameters were $2 \mathrm{~min}$ at $50^{\circ} \mathrm{C}$ for UDG incubation and $10 \mathrm{~min}$ at $95^{\circ} \mathrm{C}$ for $\mathrm{Am}$ pliTaq enzyme activation followed by 40 cycles of $15 \mathrm{~s}$ at $95^{\circ} \mathrm{C}$ and $60 \mathrm{~s}$ at $60^{\circ} \mathrm{C}$. Ct values were based on thresholds determined by the StepOnePlus software. Samples were analyzed together with the corresponding no-template and minus-RT controls. Reaction efficiencies for each assay were calculated from serial dilutions of cDNA. All quantitative PCR data were analyzed using the relative expression software tool REST 2009, version 2.0.13 (Pfaffl et al., 2002), which uses a hypothesis test to determine significant differences between control and sample groups. The software provides proper error propagation and robust statistical analysis by using a random reallocation algorithm with 10,000 iterations. Hypoxanthine guanine phosophoribosyltransferase (Hprt) was selected as reference gene for relative quantification because its expression levels did not differ significantly between experimental and control groups.

\section{Results}

We used two different models of lateonset hypothyroidism to demonstrate an effect of $\mathrm{TH}$ on adult cone opsin expression (Fig. 1). Adult C57BL/6J mice that were rendered hypothyroid by 12 weeks of treatment with the antithyroid drugs MMI and perchlorate, showed drastically reduced serum $\mathrm{TH}$ levels (free and total T3 and T4) (Fig. 2) and a significantly changed pattern of cone opsin expression (Fig. 3), resembling that in mice deficient in thyroid receptor function during development ( $\mathrm{Ng}$ et al., 2001; Roberts et al., 2006; Applebury et al., 2007; Pessôa et al., 2008; Lu et al., 2009). In dorsal retina, where wild-type mice have a majority of M-cones and a minority of S-cones (Fig. 3, top panel, control) (Szél et al., 1992; Applebury et al., 2000), hypothyroid mice expressed S-opsin in all cones and had levels of M-opsin expression reduced (Fig. 3, top panel, hypothyroid). In ventral retina, where wild-type mice coexpress $\mathrm{M}$ - and S-opsin in most cones (Applebury et al., 2000), hypothyroid mice markedly reduced M-opsin expression in all cones (Fig. 3, bottom panel, hypothyroid). Termination of antithyroid treatment restored normal $\mathrm{TH}$ levels (Fig. 2) and the normal pattern of opsin expression within 12 weeks (Fig. 3, recovery). Brown Norway rats showed similar shifts in serum iodothyronine levels (Fig. 4) and cone opsin patterns (Fig. 5) after antithyroid treatment. Because rats express only one opsin in nearly all adult cones (only $3 \%$ of the cones coexpress both opsins) and their S-opsin cones comprise a minority population at $\sim 10 \%$ of all cones across the entire retina (Szél and Röhlich, 1992; Szél et al., 1994; Ortín-Martínez et al., 2010), the hypothyroid
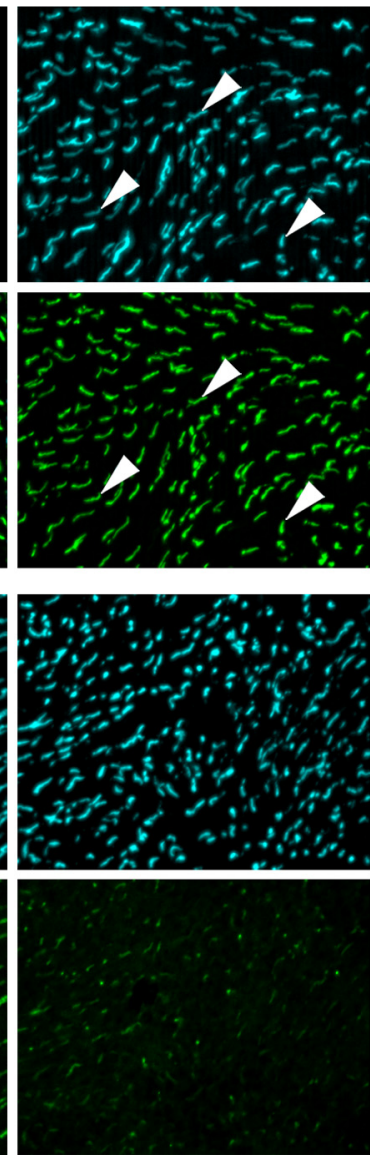

recovery
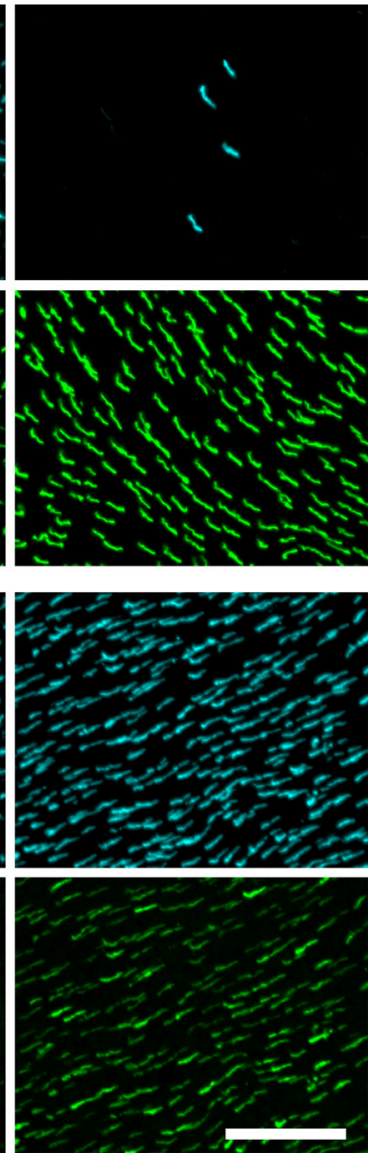

3. Cone photoreceptors in adult C57BL mice switch opsin on changes in serum TH concentrations. S- and M-opsin expression in matching fields of dorsal and ventral retina ( 75 and $50 \%$ eccentricity, respectively). Systemic hypothyroidism induced terminally differentiated M-cones to activate S-opsin in cones in dorsal retina and repress $\mathrm{M}$-opsin (arrowheads). As a result, all $\mathrm{M}$-cones also expressed S-opsin. Restoration of normal serum TH levels recovered the normal cone pattern. Scale bar, $50 \mu \mathrm{m}$.
fT3 (pmol/L)

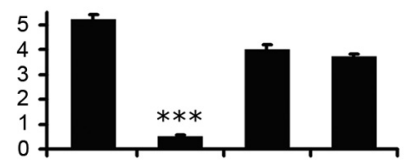

tT3 (nmol/L)

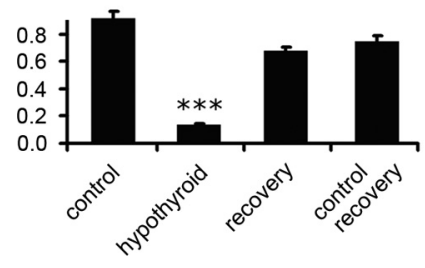

$\mathrm{fT} 4$ (pmol/L)

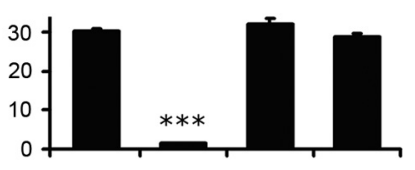

tT4 (nmol/L)

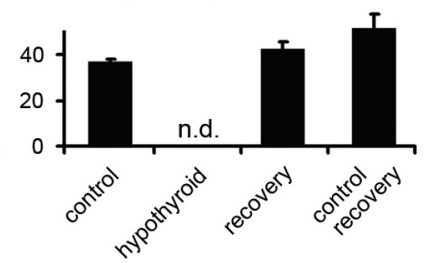

Figure 4. Serum iodothyronine levels (free and total T3 and T4) of Brown Norway rats used for cone opsin immunostaining. Data are shown as mean \pm SEM $(n=5)$ and compared with one-way ANOVA after passing the Kolmogorov-Smirnov test for normality. ${ }^{* *} p<0.001$ at $\alpha=0.05$. n.d., Not detectable.

reversible activation of S-opsin in $\mathrm{M}$-cones and the decrease in $\mathrm{M}$-opsin appeared particularly pronounced.

We also assessed changes in the expression of selected photoreceptor-related genes induced by the systemic suppression of thyroid hormone (Fig. 6). RT-qPCR showed a significant decrease of Opn1mw (M-opsin) transcript in RNA extracts from whole retinas, in line with the overall lower M-opsin signal ob- 

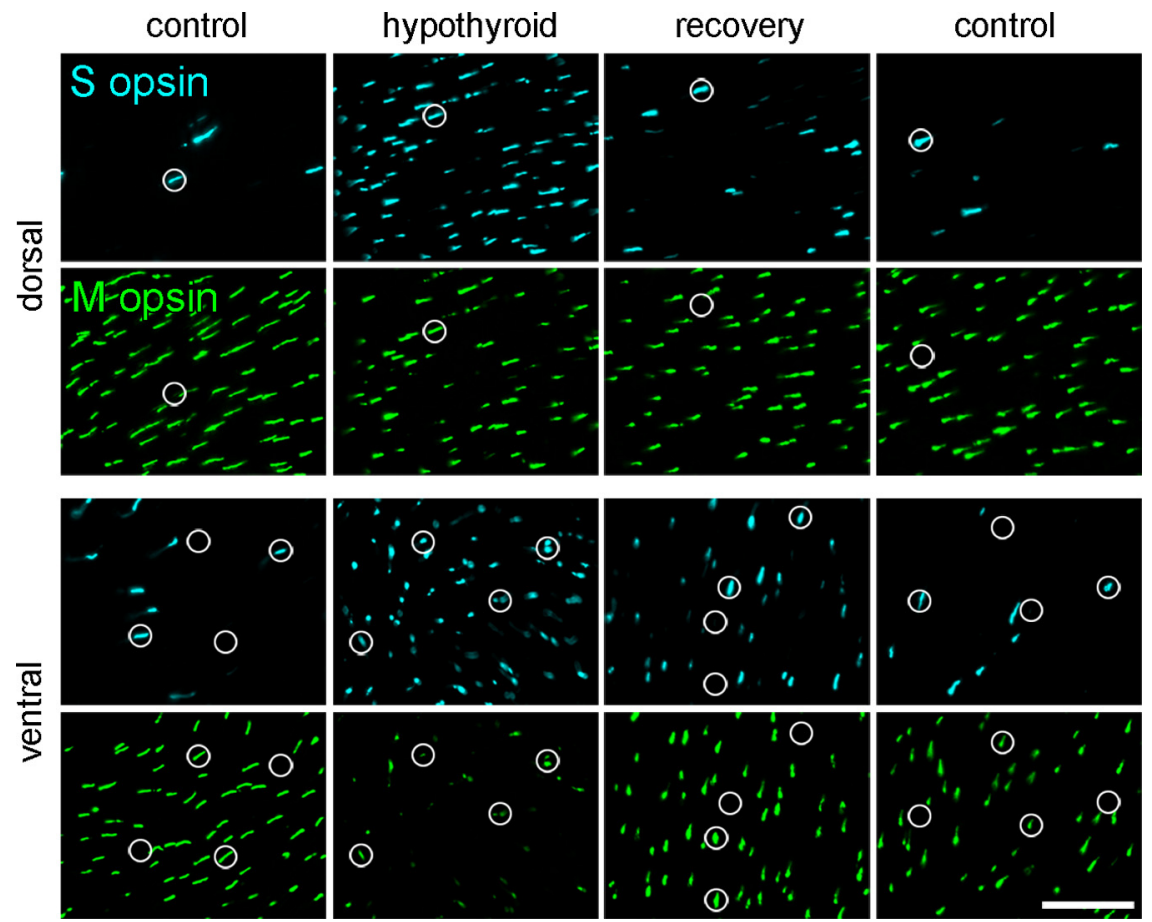

Figure 5. Cone photoreceptors in adult Brown Norway rats switch opsin on changes in serum TH concentration. S-and M-opsin expression in matching fields of dorsal and ventral retina. Adult rat cones expressed only one of the two cone opsins (Szél et al., 1994), S or M (examples indicated by circles). On induction of hypothyroidism, M-cones turned on S-opsin to coexpress both pigments in a single cell, but after recovery, cones expressed either M-opsin or S-opsin exclusively. Note that, in hypothyroid retinas, $M$-opsin was repressed, whereas $S$-opsin was activated. Scale bar, $50 \mu \mathrm{m}$.

served in individual cone photoreceptors by immunohistochemistry (Fig. 3). Opn1sw (S-opsin) expression was not significantly altered, although the number of immunolabeled S-opsin cones was significantly higher in the dorsal retina of hypothyroid animals (Fig. 3, top panel, hypothyroid). This apparent discrepancy between anatomical and molecular data may be interpreted by different effects of the hypothyroid treatment on cones in dorsal and ventral retina. In hypothyroid mice, S-opsin immunosignal in ventral cones appeared lower than in the controls (Fig. 3), which may counterbalance effects of an increase in dorsal S-opsin cones on total retinal Opn1sw mRNA levels (see Discussion). We found iodothyronine deiodinase type 2 (Dio2), encoding the enzyme that in the CNS locally synthesizes the active hormone triiodothyronine (T3) from its precursor thyroxine (T4), significantly upregulated. Conversely, Dio3, encoding the enzyme catabolizing TH, was significantly downregulated. Together, this indicates a decline of $\mathrm{TH}$ levels in the retina (see Discussion). Expression of the conespecific thyroid receptor TR $\beta 2$ (Thrb2) was unchanged. Similarly unchanged were the expression levels of rhodopsin (Rho, rod opsin), neural retina leucine zipper protein $(\mathrm{Nrl})$, and the nuclear receptor $\mathrm{Nr} 2 \mathrm{e3}$, the latter two transcription factors playing crucial roles in photoreceptor differentiation.

We further established a role of $\mathrm{TH}$ in adult cone opsin regulation using congenitally athyroid $\mathrm{Pax} 8^{-1-}$ mice (Mansouri et al., 1998), characterized by reduced serum TH levels (Friedrichsen et al., 2003) and an aberrant cone pattern that is similar to that of MMI-treated mice and is maintained into adulthood (assessed up to postnatal week 22) (Glaschke et al., 2010). Pax8 $8^{-1-}$ mice rendered euthyroid (fT3, $4.9 \pm 0.4 \mathrm{pM}$; $\mathrm{tT} 4,34 \pm 17 \mathrm{nM} ; n=2$ ) for the first 12 postnatal weeks by subcutaneous injections of T4 developed and maintained the wild-type pattern of cone opsins (Fig. 7A). Termination of T4 replacement at postnatal week 4, when the mature pattern of cones is established (Szél et al., 1993), reverted serum TH (fT3, $1.9 \pm 0.1 \mathrm{pm;} \mathrm{tT4,} \mathrm{not} \mathrm{detectable;}$ $n=3$ ) and cone opsins to the mutant pattern within 8 weeks (Fig. $7 B$ ).

Neither deletion of $\operatorname{Pax} 8$ (Glaschke et al., 2010) nor MMI treatment (Fig. 8) affected total cone number, leaving open whether changes in cone opsin patterns are attributable to shifts in opsin expression in persisting differentiated cones or to the selective loss of mature cones and the subsequent appearance of newly generated cones with different opsin expression profiles. To assess whether cell death and the generation of new cones from retinal progenitors account for the observed changes in opsin patterns, we used terminal deoxynucleotidyl transferasemediated biotinylated UTP nick end labeling (TUNEL) staining and determined the presence of markers of apoptosis and proliferation with antibodies against activated caspase- 3 and Ki67, respectively. No pyknotic TUNEL-positive nuclei were found (data not shown) and neither caspase-3+ nor Ki67+ profiles were identified in the retinas of adult (21week-old) wild-type mice or in agematched animals treated with MMI for 8 weeks, when first changes in cone opsin expression were safely detectable immunohistochemically (Fig. 9). In contrast, retinas of newborn C57BL6 mice that exhibit apoptosis and proliferation clearly stained positive for both indicators (Fig. 9).

\section{Discussion}

The present results provide first evidence for an unexpected plasticity of cone opsin regulation in the adult mammalian retina and imply a role for $\mathrm{TH}$ in the maintenance of spectral identity in terminally differentiated, mature cone photoreceptors. Opsin switches in postmitotic photoreceptors are well known in the developing mammalian retina, with ultraviolet/blue (SWS1) opsin expression preceding green (MWS/LWS) opsin expression (Szél et al., 1994; Cornish et al., 2004) and have been observed, during metamorphosis, in the larval eye of the fruit fly (Sprecher and Desplan, 2008) and in young fish (Gan and Novales Flamarique, 2010; references therein). In the retina of juvenile salmonids (alevin and parr stages), for example, "single cones" undergo a $\mathrm{TH}$-induced switch in opsin expression from ultraviolet (SWS1) to blue (SWS2) opsin (Cheng and Flamarique, 2007; Cheng et al., 2009), with the expression levels of thyroid receptor isoforms $\operatorname{TR} \alpha$ and $\operatorname{TR} \beta$ raising after developmental or experimentally induced surges in thyroid hormone (Raine and Hawryshyn, 2009; Gan and Novales Flamarique, 2010; Raine et al., 2010). In adult mammals, comparable opsin shifts have not been described, except minor circadian oscillations of opsin transcript levels (von Schantz et al., 1999), which are thought not to alter the spectral phenotype of the photoreceptor. In fact, our finding contradicts a previous study (Applebury et al., 2007) yielding no $\mathrm{TH}$ effect on cone opsin expression after subjecting adult mice to hypothyroid treatment for only 2 weeks. A possible explanation for this discrepancy is that changes in cone opsin 
expression after pharmacological suppression of $\mathrm{TH}$ occur at a much slower timescale, consistent with the known $\mathrm{TH}$ homeostasis capability of central neural tissue, which maintains physiological levels of T3 for some time, even under conditions of peripheral hypothyroidism (Kundu et al., 2006), and consistent with our observation that changes in the expression pattern of S- and M-cone opsin were first detectable 5-7 weeks after serum $\mathrm{TH}$ concentrations had decreased to hypothyroid levels.

Although we did not directly measure $\mathrm{TH}$ tissue concentration, our finding of significantly altered Dio2 and Dio3 transcript levels in the retinas of MMI-treated mice (Fig. 6) suggests that the changes in serum hormone levels indeed translated into equivalent changes in the retina. Dio2 and Dio 3 expression is under control of $\mathrm{TH}$ and regulated by a negative-feedback loop (Bianco and Larsen, 2005; Gereben et al., 2008). A decrease in tissue levels of TH increases Dio2 expression, counteracting the decrease of T3 by conversion of T4 to T3, and decreases Dio 3 expression to counteract TH degradation. As a consequence, a relative increase in Dio2 transcript levels together with a relative decrease in Dio3 transcript levels, as observed in the retinas of MMI-treated mice, strongly indicate low $\mathrm{TH}$ tissue levels (Gereben et al., 2008).

Although the lower levels of M-opsin transcript in adult MMI-treated mice are consistent with a decrease in M-opsin immunosignal, no changes in levels of S-opsin mRNA were observed compared with untreated control retinas, despite a significant increase in S-opsin-immunopositive cones in dorsal retina. We hypothesize that, in hypothyroid mice, activation of S-opsin in dorsal cones is counterbalanced by diminished S-opsin transcription in ventral cones, which would not be resolved in our qPCR assay of total retinal extracts.

We find that expression of Thrb2, a nuclear transcription factor with key role in the repression of S-opsin and induction of $\mathrm{M}$-opsin expression during development (Ng et al., 2001), remains unchanged. This suggests that TR $\beta 2$ levels in individual cones are not affected by decreasing serum TH concentrations. Alternatively, similar to S-opsin mRNA, TR $\beta 2$ expression may be topographically rearranged in a manner leaving total retinal transcript level(s) of TR $\beta 2$ unaltered. It is not yet established whether during early development cone-specific expression of TR $\beta 2$ is dorsoventrally graded (Fujieda et al., 2009) or not (Roberts et al., 2005; Applebury et al., 2007), and available methodology appears to lack sufficient sensitivity to resolve the spatiotemporal characteristics of $\operatorname{Tr} \beta 2$ expression in the adult retina with cellular precision (Applebury et al., 2007; Ng et al., 2009) (our own attempts with riboprobes), likely because of low TR $\beta 2$ levels pres-

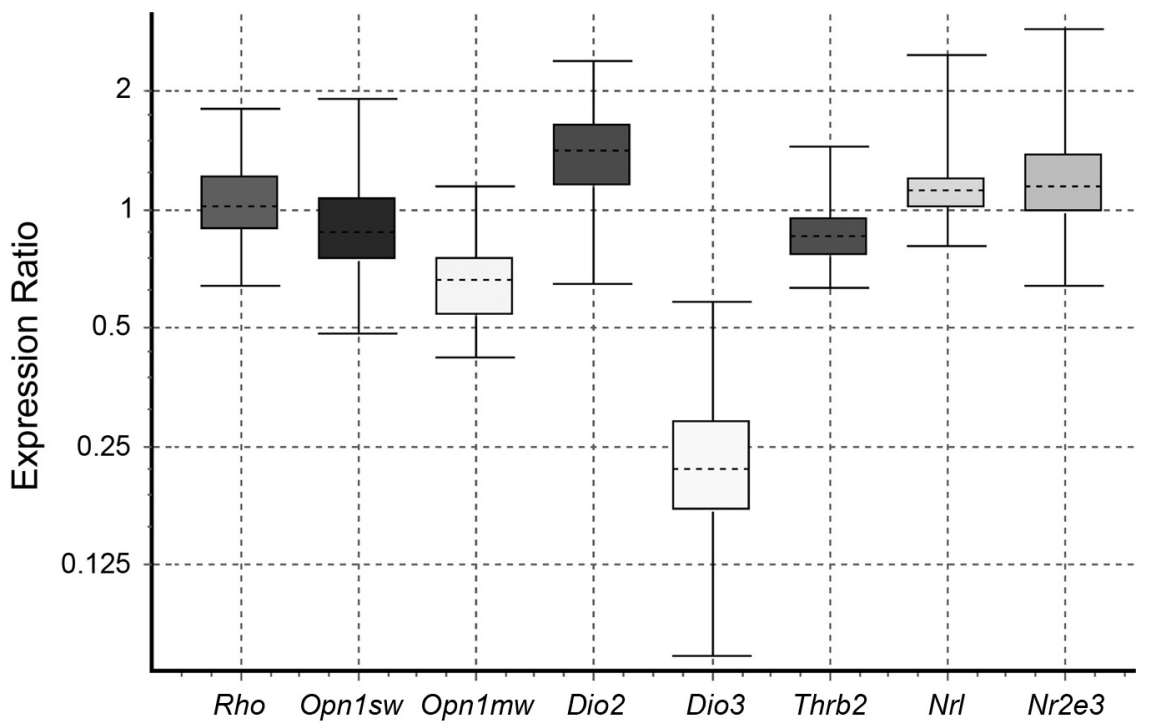

\begin{tabular}{|c|c|c|c|c|c|c|c|}
\hline Gene & Type & React. Eff. & Expression & Std. Error & $\mathbf{9 5 \%}$ C.I. & P(H1) & Result \\
\hline Hprt & REF & 0.855 & 1 & - & - & - & $\leftrightarrow$ \\
\hline Rho & TRG & 0.857 & 1.031 & $0.775-1.379$ & $0.645-1.610$ & 0.766 & $\leftrightarrow$ \\
\hline Opn1sw & TRG & 0.879 & 0.897 & $0.660-1.243$ & $0.496-1.570$ & 0.387 & $\leftrightarrow$ \\
\hline Opn1mw & TRG & 0.886 & 0.659 & $0.502-0.824$ & $0.453-1.067$ & 0.001 & $\downarrow$ \\
\hline Dio2 & TRG & 0.942 & 1.363 & $0.940-1.874$ & $0.733-2.223$ & 0.022 & $\uparrow$ \\
\hline Dio3 & TRG & 0.836 & 0.216 & $0.146-0.334$ & $0.080-0.511$ & 0 & $\downarrow$ \\
\hline Thrb2 & TRG & 0.937 & 0.881 & $0.730-1.074$ & $0.653-1.366$ & 0.086 & $\leftrightarrow$ \\
\hline Nrl & TRG & 0.886 & 1.173 & $0.976-1.258$ & $0.872-2.424$ & 0.118 & $\leftrightarrow$ \\
\hline Nr2e3 & TRG & 0.871 & 1.198 & $0.879-1.573$ & $0.707-2.506$ & 0.188 & $\leftrightarrow$ \\
\hline
\end{tabular}

Figure 6. Thyroid hormone changes mRNA expression in the adult mouse retina. RT-qPCR confirmed upregulation of iodothywere downregulated compared with controls. In MMI-treated mice, S-opsin (Opn1sw) transcript levels were not significantly different from controls in homogenates of entire retinas, although immunohistochemistry clearly shows upregulation in dorsa (a) sin), Thrb2 (thyroid hormone receptor $\beta 2$ ), $N r$ (neural retina leucine zipper), and $N r 2 e 3$ (nuclear receptor subfamily 2, group E, . Relative gene expression was normalized to Hprt expression as determined by REST 2009, version 2.0.13. The boxes resent minimum and maximum observations. $\mathrm{P}(\mathrm{H1})$, Probability of alternate hypothesis that difference between sample and control groups is attributable only to chance; TRG, target; REF, reference.

ent. Future efforts therefore should evaluate TR $\beta 2$ expression in the wild-type compared with the hypothyroid adult retina.

Our results show that the nuclear receptor $\mathrm{Nr} 2 \mathrm{e} 3$ and the neural retina leucine zipper transcription factor $\mathrm{Nrl}$, key transcriptionregulatory factors that determine rod versus $\mathrm{M}$-cone or S-cone cell fate, are transcribed at wild-type levels. Mutations in either gene cause "enhanced S-cone syndrome," characterized by a loss of rods and an excess of S-opsin-expressing cones (Haider et al., 2001, 2006; Mears et al., 2001; Yoshida et al., 2004), because precursors that are committed to become rods convert to cones. Unchanged transcript levels of $\mathrm{Nrl}, \mathrm{Nr} 2 \mathrm{e3}$, and Rho in the MMI-treated mice indicate that the observed increase of S-opsin-expressing cones cannot be attributed to TH-dependent deficiencies in the Nr2e3 or Nrl pathway.

The absence of indicators for photoreceptor apoptotic cell death and proliferation together with the persistence of wild-type cone densities in MMI-treated mice indicates that the effects of $\mathrm{TH}$ on cone opsin patterns occurs through changes in opsin expression profiles in existing cones rather than the disappearance 

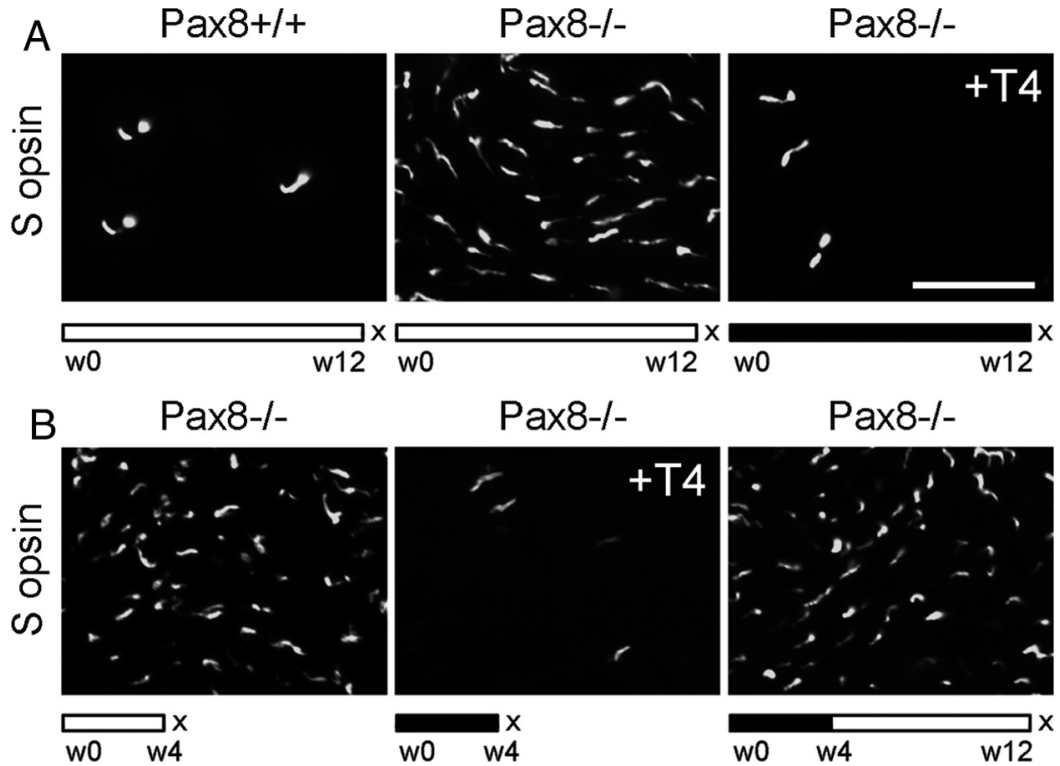

Figure 7. Thyroid hormone reversibly changes $S$-cone opsin patterns in Pax $8^{-1-}$ mice. $\boldsymbol{A}$, TH replacement to hypothyroid Pax $8^{-1-}$ mice by subcutaneous T4 injections restored the wild-type pattern of S-cone opsin expression when administered for 12 weeks. $\boldsymbol{B}$, Pax $8^{-1-}$ mutant retinas exhibited the wild-type pattern of cones after 4 weeks of T4 supplementation but reverted to the mutant S-cone opsin pattern within 8 weeks after T4 supplementation was terminated. The illustrated regions are located dorsal (75\% eccentricity) to the level of the optic disc. Scale bar, $30 \mu \mathrm{m}$. w, Postnatal week.

A
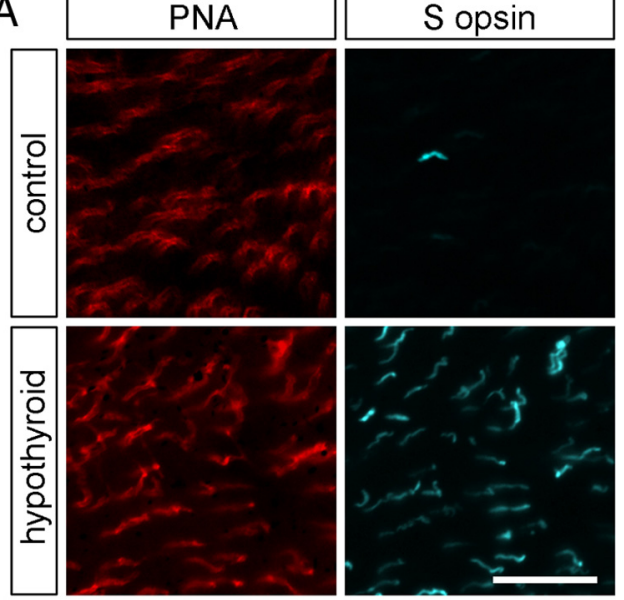

B

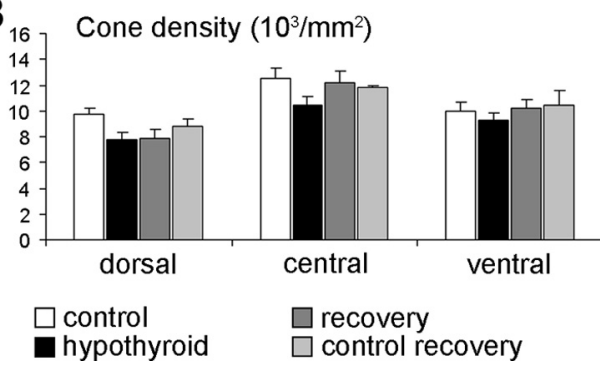

Figure 8. Induction of hypothyroidism activates S-opsin but does not increase total cone number. $\boldsymbol{A}$,Flat-mounted mouse retina labeled with S-opsin antibody (blue) and peanutagglutinin (PNA) (red) to label the total population of cones. Region illustrated is from the dorsal retina. Scale bar, $30 \mu \mathrm{m}$. $\boldsymbol{B}$, There was no significant difference in the number of PNA-positive cones between control, hypothyroid, recovery, and control recovery groups. Images were collected with a Zeiss Axio Imager.Z1 microscope at $40 \times$, and total cones were quantified from $100 \times 100 \mu \mathrm{m}$ dorsal, central, and ventral regions in retinas of each experimental group. Data are expressed as mean \pm SEM (number of animals $n=6,7,5,5$ for control, hypothyroid, recovery, control recovery group, respectively). Regions were compared with one-way ANOVA after validation of normality of data (Kolmogorov-Smirnov) and homogeneity of variances (Bartlett box F test). and generation of cones with different opsin identities. This resembles the opsin switch seen in mice deficient in thyroid receptor function during development ( $\mathrm{Ng}$ et al., 2001; Roberts et al., 2006; Applebury et al., 2007; Pessôa et al., 2008; Lu et al., 2009), and in mice that are congenitally athyroid or rendered hypothyroid during early development (Pessôa et al., 2008; Lu et al., 2009; Glaschke et al., 2010).

The molecular mechanism behind the switch of S- and M-opsins in mature mammalian cones is unclear at this point. During early development, the timing and spatial arrangement of cone opsin expression is under the control of nuclear transcription factors, including TR $\beta 2$ (Roberts et al., 2006; Applebury et al., 2007; Lu et al., 2009), retinoid X receptor $\gamma(\operatorname{RXR} \gamma)$ (Roberts et al., 2005), and members of the retinoic acid receptor-related orphan receptor family $[\operatorname{ROR} \alpha$ (Fujieda et al., 2009); ROR $\beta$ (Srinivas et al., 2006)]. Ligand $(\mathrm{TH})$-activated TR $\beta 2$ and $\operatorname{RXR} \gamma$ synergistically repress $\mathrm{S}$-opsin starting in the embryonic period (Roberts et al., 2005). TH-activated TR $\beta 2$ and ROR $\beta$ selectively activate $\mathrm{M}$ - and S-opsin, respectively (Roberts et al., 2006; Srinivas et al., 2006; Applebury et al., 2007), whereas ROR $\alpha$ transactivates conespecific genes including S- and M-opsin (Fujieda et al., 2009). It is believed that cone type-specific signatures and dorsoventral gradients of S- and M-opsin are established early by the graded availability of regulatory factors including TH (Roberts et al., 2006) and TR $\beta 2$ (Fujieda et al., 2009) and that promoter silencing by DNA methylation and histone modification achieves stable, long-term states of S-opsin repression and M-opsin activation in differentiated cones. Therefore, declining concentrations of tissue $\mathrm{TH}$ in hypothyroid retinas may trigger pathways that remodel silenced chromatin complexes and lead to chromatin states that reopen promoters for transcriptional regulation. A global analysis of TH target genes has not been performed in the adult mammalian retina. However, in the adult rodent brain, relatively few TH-dependent genes have been identified, with no apparent involvement of components of the chromatin modification pathway (Quignodon et al., 2007). This opens the possibility that transactivators of S- and M-opsin with regulatory function during early development also play a role for the maintenance of opsin identity in mature cones. Interestingly, $\mathrm{TR} \beta 2, \operatorname{RXR} \gamma$, $\operatorname{ROR} \alpha$, and $\operatorname{ROR} \beta$ remain expressed in the adult retina (Janssen et al., 1999; Mori et al., 2001; Srinivas et al., 2006; Applebury et al., 2007; Fujieda et al., 2009) but their role in differentiated cones is unexplored. Future research should devise methods including conditional, cell-specific gene manipulation to reveal the role of the various transcription factors in cone development and homeostasis.

Finally, our results demonstrate that opsin expression in mature mammalian cones switches regardless of which color cone pattern is established. Mice and rats have different distributions of the spectral cone types across the retina. In rat, like in most mammals, most cones express a single opsin, $\mathrm{S}$ or $\mathrm{M}$, in a mosaiclike pattern, with S-cones comprising a minority of the total cone population $(\sim 10 \%)$ across the entire retina (Fig. 3) (Szél and 
Röhlich, 1992; Szél et al., 1994; OrtínMartínez et al., 2010). By contrast, in mouse most cones coexpress $S$ - and $\mathrm{M}$-opsin (dual pigment cones) in opposing distribution gradients along the dorsal (M-opsin-high) to ventral (S-opsin-high) axis (Fig. 2) (Szél et al., 1992; Applebury et al., 2000). The effects of thyroid hormone on S- and M-opsin expression in adult rat and mouse retina are identical, suggesting that cone opsin expression in adult mammals is susceptible to alterations in $\mathrm{TH}$ availability with possible functional implications. Because changes in serum $\mathrm{TH}$ occur as human disorders (e.g., as a consequence of dietary iodine deficiency or thyroidectomy), reversible cone opsin switches may also affect the adult human retina and impair visual function, particularly color vision. In clinical tests, this may go unnoticed as metabolic and neurological symptoms of adult-onset hypothyroidism can be severe and are rapidly treated.

\section{References}

Ahnelt PK, Kolb H (2000) The mammalian photoreceptor mosaic-adaptive design. Prog Retin Eye Res 19:711-777.

Applebury ML, Antoch MP, Baxter LC, Chun LL, Falk JD, Farhangfar F, Kage K, Krzystolik MG, Lyass LA, Robbins JT (2000) The murine cone photoreceptor: a single cone type expresses both $\mathrm{S}$ and $\mathrm{M}$ opsins with retinal spatial patterning. Neuron 27:513-523.

Applebury ML, Farhangfar F, Glösmann M, Hashimoto K, Kage K, Robbins JT, Shibusawa N, Wondisford FE, Zhang H (2007) Transient expression of thyroid hormone nuclear receptor TRbeta2 sets $S$ opsin patterning during cone photoreceptor genesis. Dev Dyn 236:1203-1212.

Bianco AC, Larsen PR (2005) Cellular and structural biology of the deiodinases. Thyroid 15:777-786.

Cheng CL, Flamarique IN (2007) Chromatic organization of cone photoreceptors in the retina of rainbow trout: single cones irreversibly switch from UV (SWS1) to blue (SWS2) light sensitive opsin during natural development. J Exp Biol 210:4123-4135.

Cheng CL, Gan KJ, Flamarique IN (2009) Thyroid hormone induces a timedependent opsin switch in the retina of salmonid fishes. Invest Ophthalmol Vis Sci 50:3024-3032.

Cornish EE, Xiao M, Yang Z, Provis JM, Hendrickson AE (2004) The role of opsin expression and apoptosis in determination of cone types in human retina. Exp Eye Res 78:1143-1154.

Friedrichsen S, Christ S, Heuer H, Schäfer MK, Mansouri A, Bauer K, Visser TJ (2003) Regulation of iodothyronine deiodinases in the Pax $8^{-1-}$ mouse model of congenital hypothyroidism. Endocrinology 144:777-784.

Fujieda H, Bremner R, Mears AJ, Sasaki H (2009) Retinoic acid receptorrelated orphan receptor $\alpha$ regulates a subset of cone genes during mouse retinal development. J Neurochem 108:91-101.

Gan KJ, Novales Flamarique I (2010) Thyroid hormone accelerates opsin expression during early photoreceptor differentiation and induces opsin switching in differentiated TR $\alpha$-expressing cones of the salmonid retina. Dev Dyn 239:2700-2713.

Gereben B, Zeöld A, Dentice M, Salvatore D, Bianco AC (2008) Activation and inactivation of thyroid hormone by deiodinases: local action with general consequences. Cell Mol Life Sci 65:570-590.

Glaschke A, Glösmann M, Peichl L (2010) Developmental changes of cone opsin expression but not retinal morphology in the hypothyroid Pax8 knockout mouse. Invest Ophthalmol Vis Sci 51:1719-1727.

Glösmann M, Steiner M, Peichl L, Ahnelt PK (2008) Cone photoreceptors and potential UV vision in a subterranean insectivore, the European mole. J Vis 8:23.1-12.

Haider NB, Naggert JK, Nishina PM (2001) Excess cone cell proliferation hypothyroid
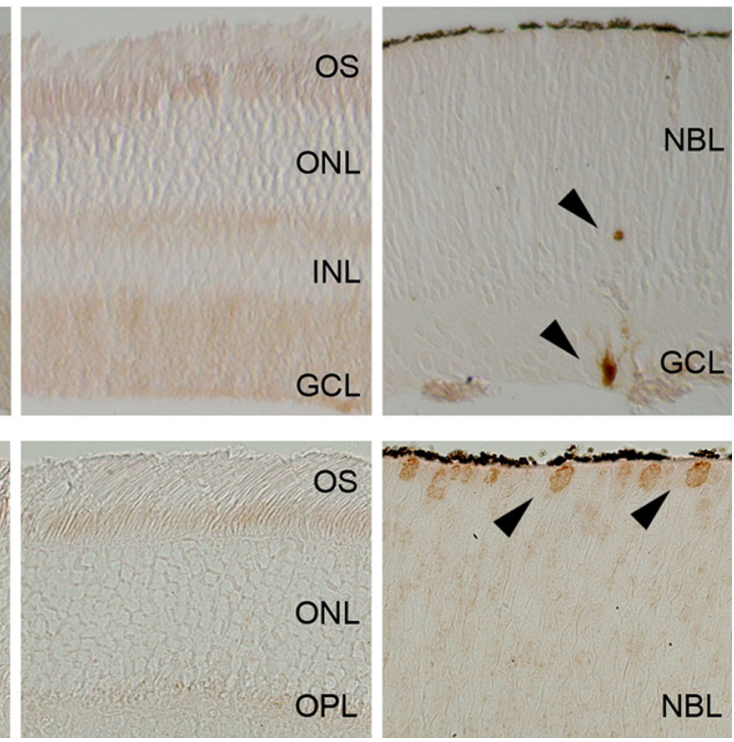

os

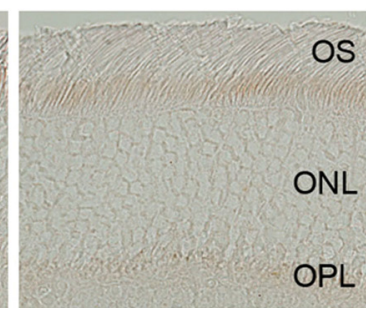

NBL

Figure 9. Apoptosis and cell proliferation in the adult mouse retina. Activated caspase-3 and Ki67 immunoreactivity were the retina of newborn mice serving as a positive control but absent in all retinal layers of adult wild-type and MMItreated C57BL/6 mice. 0S, Outer segment layer; ONL, outer nuclear layer; INL, inner nuclear layer; GCL, ganglion cell layer; OPL, outer plexiform layer; NBL, neuroblast layer.

ation in rd7/rd7 mice. Hum Mol Genet 10:1619-1626.

Haider NB, Demarco P, Nystuen AM, Huang X, Smith RS, McCall MA, Naggert JK, Nishina PM (2006) The transcription factor Nr2e3 functions in retinal progenitors to suppress cone cell generation. Vis Neurosci 23:917-929.

Ientile R, Macaione S, Russo P, Pugliese G, Di Giorgio RM (1984) Phenolic and tyrosyl ring deiodination in thyroxine from rat retina during postnatal development. Eur J Biochem 142:15-19.

Janssen JJ, Kuhlmann ED, van Vugt AH, Winkens HJ, Janssen BP, Deutman AF, Driessen CA (1999) Retinoic acid receptors and retinoid X receptors in the mature retina: subtype determination and cellular distribution. Curr Eye Res 19:338-347.

Kundu S, Pramanik M, Roy S, De J, Biswas A, Ray AK (2006) Maintenance of brain thyroid hormone level during peripheral hypothyroid condition in adult rat. Life Sci 79:1450-1455.

Lu A, Ng L, Ma M, Kefas B, Davies TF, Hernandez A, Chan CC, Forrest D (2009) Retarded developmental expression and patterning of retinal cone opsins in hypothyroid mice. Endocrinology 150:1536-1544.

Mansouri A, Chowdhury K, Gruss P (1998) Follicular cells of the thyroid gland require Pax8 gene function. Nat Genet 19:87-90.

Mears AJ, Kondo M, Swain PK, Takada Y, Bush RA, Saunders TL, Sieving PA, Swaroop A (2001) Nrl is required for rod photoreceptor development. Nat Genet 29:447-452.

Mori M, Ghyselinck NB, Chambon P, Mark M (2001) Systematic immunolocalization of retinoid receptors in developing and adult mouse eyes. Invest Ophthalmol Vis Sci 42:1312-1318.

Ng L, Hurley JB, Dierks B, Srinivas M, Saltó C, Vennström B, Reh TA, Forrest D (2001) A thyroid hormone receptor that is required for the development of green cone photoreceptors. Nat Genet 27:94-98.

Ng L, Ma M, Curran T, Forrest D (2009) Developmental expression of thyroid hormone receptor beta2 protein in cone photoreceptors in the mouse. Neuroreport 20:627-631.

Ortín-Martínez A, Jiménez-López M, Nadal-Nicolás FM, Salinas-Navarro M, Alarcón-Martínez L, Sauvé Y, Villegas-Pérez MP, Vidal-Sanz M, AgudoBarriuso M (2010) Automated quantification and topographical distribution of the whole population of S- and L-cones in adult albino and pigmented rats. Invest Ophthalmol Vis Sci 51:3171-3183.

Peichl L (2005) Diversity of mammalian photoreceptor properties: adaptations to habitat and lifestyle? Anat Rec A Discov Mol Cell Evol Biol 287:1001-1012.

Pessôa CN, Santiago LA, Santiago DA, Machado DS, Rocha FA, Ventura DF, 
Hokoç JN, Pazos-Moura CC, Wondisford FE, Gardino PF, OrtigaCarvalho TM (2008) Thyroid hormone action is required for normal cone opsin expression during mouse retinal development. Invest Ophthalmol Vis Sci 49:2039-2045.

Pfaffl MW, Horgan GW, Dempfle L (2002) Relative expression software tool (REST) for group-wise comparison and statistical analysis of relative expression results in real-time PCR. Nucleic Acids Res 30:e36.

Quignodon L, Grijota-Martinez C, Compe E, Guyot R, Allioli N, Laperrière D, Walker R, Meltzer P, Mader S, Samarut J, Flamant F (2007) A combined approach identifies a limited number of new thyroid hormone target genes in post-natal mouse cerebellum. J Mol Endocrinol 39:17-28.

Raine JC, Hawryshyn CW (2009) Changes in thyroid hormone reception precede SWS1 opsin downregulation in trout retina. J Exp Biol 212: 2781-2788.

Raine JC, Coffin AB, Hawryshyn CW (2010) Systemic thyroid hormone is necessary and sufficient to induce ultraviolet-sensitive cone loss in the juvenile rainbow trout retina. J Exp Biol 213:493-501.

Roberts MR, Hendrickson A, McGuire CR, Reh TA (2005) Retinoid X receptor (gamma) is necessary to establish the S-opsin gradient in cone photoreceptors of the developing mouse retina. Invest Ophthalmol Vis Sci 46:2897-2904.

Roberts MR, Srinivas M, Forrest D, Morreale de Escobar G, Reh TA (2006) Making the gradient: thyroid hormone regulates cone opsin expression in the developing mouse retina. Proc Natl Acad Sci U S A 103:6218-6223.

Sprecher SG, Desplan C (2008) Switch of rhodopsin expression in terminally differentiated Drosophila sensory neurons. Nature 454:533-537.
Srinivas M, Ng L, Liu H, Jia L, Forrest D (2006) Activation of the blue opsin gene in cone photoreceptor development by retinoid-related orphan receptor beta. Mol Endocrinol 20:1728-1741.

Szél A, Röhlich P (1992) Two cone types of rat retina detected by anti-visual pigment antibodies. Exp Eye Res 55:47-52.

Szél A, Röhlich P, Caffé AR, Juliusson B, Aguirre G, van Veen T (1992) Unique topographic separation of two spectral classes of cones in the mouse retina. J Comp Neurol 325:327-342.

Szél A, Röhlich P, Mieziewska K, Aguirre G, van Veen T (1993) Spatial and temporal differences between the expression of short- and middle-wave sensitive cone pigments in the mouse retina: a developmental study. J Comp Neurol 331:564-577.

Szél A, van Veen T, Röhlich P (1994) Retinal cone differentiation. Nature 370:336.

von Schantz M, Lucas RJ, Foster RG (1999) Circadian oscillation of photopigment transcript levels in the mouse retina. Brain Res Mol Brain Res $72: 108-114$.

Wang Y, Macke JP, Merbs SL, Zack DJ, Klaunberg B, Bennett J, Gearhart J, Nathans J (1992) A locus control region adjacent to the human red and green visual pigment genes. Neuron 9:429-440.

Yoshida S, Mears AJ, Friedman JS, Carter T, He S, Oh E, Jing Y, Farjo R, Fleury G, Barlow C, Hero AO, Swaroop A (2004) Expression profiling of the developing and mature $\mathrm{Nrl}^{-1-}$ mouse retina: identification of retinal disease candidates and transcriptional regulatory targets of $\mathrm{Nrl}$. Hum Mol Genet 13:1487-1503. 